\title{
New-onset postoperative atrial fibrillation after aortic valve replacement: Effect on long-term survival
}

\author{
Ben M. Swinkels, MD, ${ }^{\mathrm{a}}$ Bas A. de Mol, MD, PhD, ${ }^{\mathrm{b}}$ Johannes C. Kelder, MD, PhD, MS, ${ }^{\mathrm{a}}$ \\ Freddy E. Vermeulen, $\mathrm{MD}, \mathrm{PhD},{ }^{\mathrm{c}}$ and Jurriën $\mathrm{M}$. ten Berg, $\mathrm{MD}, \mathrm{PhD}^{\mathrm{a}}$
}

\begin{abstract}
Objective: There is a paucity of data on long-term survival of new-onset postoperative atrial fibrillation (POAF) after cardiac surgery. Also, mean follow-up in previous studies is confined to a maximum of one decade. This retrospective, longitudinal cohort study was performed to determine the effect on long-term survival of new-onset POAF after aortic valve replacement (AVR) over a mean follow-up of almost 2 decades.
\end{abstract}

Methods: Kaplan-Meier survival analysis was used to determine long-term survival after AVR, performed between January 1, 1990, and January 1, 1994, in 569 consecutive patients without a history of atrial fibrillation, divided into 241 patients $(42.4 \%)$ with and 328 patients $(57.6 \%)$ without new-onset POAF. New-onset POAF was considered in multivariable analysis for decreased longterm survival. After AVR, patients with new-onset POAF were treated with the aim to restore sinus rhythm within 24 to 48 hours from onset by medication and when medication failed by direct-current cardioversion before discharge home.

Results: Mean follow-up after AVR was $17.8 \pm 1.9$ years. Incidence of new-onset POAF was $42.4 \%$. Kaplan-Meier overall cumulative survival rates at 15 years of follow-up were similar in the patients with new-onset POAF versus those without: $41.5 \%$ (95\% confidence interval [CI], 35.2-47.7) versus $41.3 \%$ (95\% CI, 36.046.7), respectively. New-onset POAF was not an independent risk factor for decreased long-term survival (hazard ratio $0.815 ; 95 \% \mathrm{CI}, 0.663-1.001 ; P=.052$ ).

Conclusions: New-onset POAF after AVR does not affect long-term survival when treatment is aimed to restore sinus rhythm before discharge home. (J Thorac Cardiovasc Surg 2017;154:492-8)

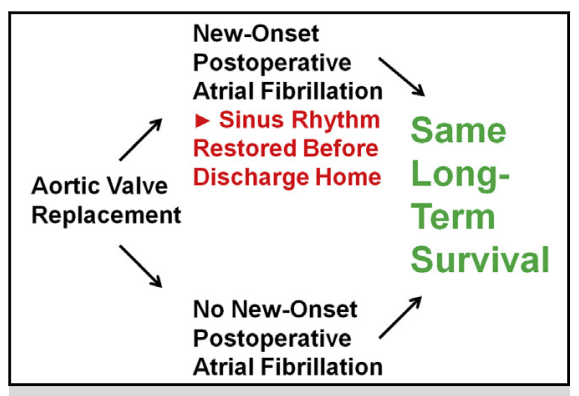

New-onset postoperative atrial fibrillation does not affect long-term survival.

\section{Central Message}

New-onset postoperative atrial fibrillation does not affect long-term survival when treatment is aimed to restore sinus rhythm before discharge home.

\section{Perspective}

New-onset postoperative atrial fibrillation after aortic valve replacement does not affect longterm survival when treatment is aimed to restore sinus rhythm before discharge home. Future studies with a prospective randomized design should be done to confirm this finding in patients undergoing different kinds of cardiac surgery.

See Editorial Commentary page 499.

See Editorial page 490.
Postoperative atrial fibrillation (POAF) after cardiac surgery is common and affects $10 \%$ to $40 \%$ of patients undergoing coronary artery bypass grafting (CABG) and more than $50 \%$ of patients undergoing valve surgery. ${ }^{1}$ Although its

From the Departments of ${ }^{\mathrm{a} C}$ ardiology and ${ }^{\mathrm{c}}$ Cardiothoracic Surgery, St Antonius Hospital, Nieuwegein; and ${ }^{\mathrm{b}}$ Department of Cardiothoracic Surgery, Academic Medical Center, Amsterdam, The Netherlands.

This work was supported by Stichting Hartenzorg St Antonius, Nieuwegein, Stichting Nuts Ohra, and the former Jacques de Jong Stichting, The Netherlands.

Received for publication May 26, 2016; revisions received Jan 27, 2017; accepted for publication Feb 20, 2017; available ahead of print April 5, 2017.

Address for reprints: Ben M. Swinkels, MD, St Antonius Hospital, Department of Cardiology, P.O. Box 2500, 3435 CM Nieuwegein, The Netherlands (E-mail: b.m.swinkels@hetnet.nl).

$0022-5223 / \$ 36.00$

Copyright (c) 2017 by The American Association for Thoracic Surgery

http://dx.doi.org/10.1016/j.jtcvs.2017.02.052 effect on long-term survival remains unclear, POAF is associated with decreased 30-day survival. ${ }^{2,3}$ Regarding newonset POAF, that is, POAF in patients without a history of atrial fibrillation (AF), the literature is sparse. Recently, incidence rates of new-onset POAF after isolated aortic valve replacement (AVR) or CABG with concomitant AVR were $28 \%$ and $39 \%$, respectively. ${ }^{4}$ New-onset POAF appeared

Scanning this QR code will take you to a supplemental video for the article. 


\section{Abbreviations and Acronyms \\ $\mathrm{AF}=$ atrial fibrillation \\ AVR $=$ aortic valve replacement \\ $\mathrm{CABG}=$ coronary artery bypass grafting \\ $\mathrm{POAF}=$ postoperative atrial fibrillation}

to affect both mental and physical health 6 months after CABG. ${ }^{5}$ In some studies, new-onset POAF was associated with decreased 30-day survival after cardiac surgery. ${ }^{6,7}$ However, in other studies it was not. ${ }^{8} 9$ In most studies, new-onset POAF affected long-term survival after cardiac surgery. ${ }^{10-13}$ However, in these studies, mostly patients undergoing $\mathrm{CABG}$, not valve surgery, were included. Also, mean follow-up was confined to one decade. In one study, new-onset POAF affected long-term survival after CABG, but not after isolated valve or combined valve-CABG procedures. ${ }^{14}$ However, mean follow-up was confined to almost 8 years. Recently, new-onset POAF did not affect long-term survival after cardiac surgery. ${ }^{15}$ However, mean follow-up was confined to almost one decade. We aimed to determine the effect on long-term survival of new-onset POAF after AVR over a mean follow-up of almost 2 decades.

\section{MATERIALS AND METHODS}

In this retrospective longitudinal cohort study, 569 consecutive patients without a history of $\mathrm{AF}$ were followed for a mean of $17.8 \pm 1.9$ years after AVR with or without concomitant CABG, performed between January 1, 1990, and January 1, 1994 (Video 1). Thirty-day and long-term survival rates were determined in 2 subgroups: 241 patients $(42.4 \%)$ with and 328 patients $(57.6 \%)$ without new-onset POAF. New-onset POAF was defined as electrocardiographically documented AF lasting for at least several hours, occurring after AVR when the patient was still admitted,

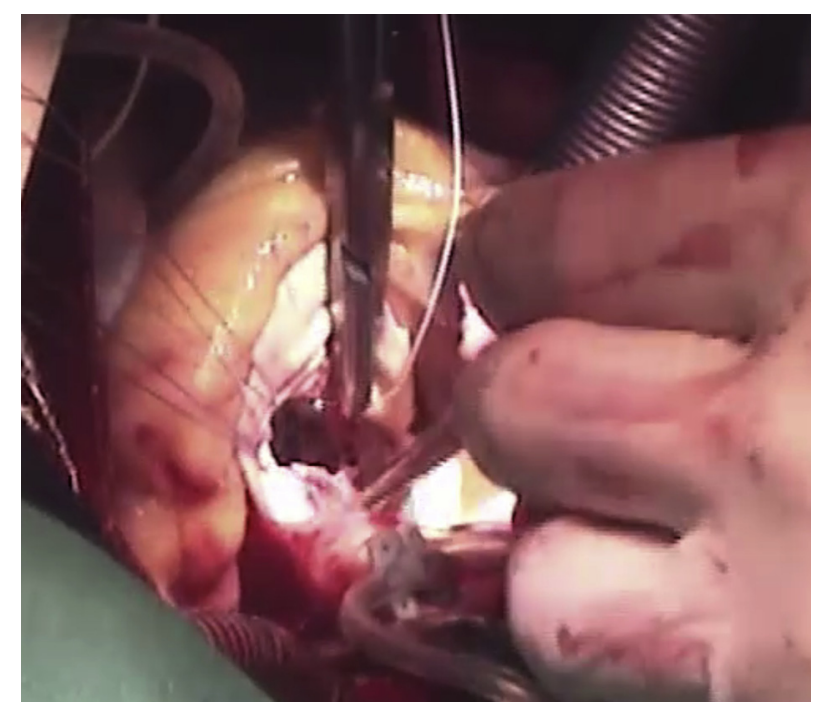

VIDEO 1. Aortic valve replacement procedure, shown from cannulation until chest closure. Because of permanent atrial fibrillation (unlike the study patients), an atrial clip also was placed. Video available at: http:// www.jtcvsonline.org/article/S0022-5223(17)30414-2/addons. and affecting only patients without a history of AF. Standard therapy to prevent new-onset POAF was prescribing sotalol in patients who were not on beta-blocker therapy before AVR or calcium-antagonists in patients with chronic obstructive pulmonary disease the day after AVR. Patients who were on beta-blocker therapy before AVR were maintained on betablocker therapy, which was continued after they were discharged home. Treatment of new-onset POAF was aimed to restore sinus rhythm within 24 to 48 hours from onset by the use of medication, mostly by temporarily prescribing a greater dose of sotalol or a beta-blocker or by temporarily adding digoxin to beta-blocker or calcium-antagonist therapy. When medication failed to restore sinus rhythm within 24 to 48 hours from onset, direct-current cardioversion before discharge was performed. Patients still in $\mathrm{AF}$ at discharge underwent direct-current cardioversion within 6 weeks from discharge. Irrespective of the occurrence of new-onset POAF, oral anticoagulants were prescribed in all patients from the day after AVR, for life in case of mechanical AVR and for 3 months in case of biologic AVR Follow-up data were obtained from our own or referring cardiology departments, general practitioners, and telephone calls to patients and relatives. The study object was agreed on by the Committee on Ethics and Medical Experiments of the St Antonius Hospital, Nieuwegein, The Netherlands Funding agencies did not play a role in data interpretation.

\section{Definitions of Baseline Characteristics}

Baseline characteristics were defined as follows. Recent or old myocardial infarction was defined as myocardial infarction occurring $\leq 6$ weeks or $>6$ weeks before operation, respectively. Peripheral arterial disease was defined as claudication or surgical or percutaneous intervention on the peripheral arteries, excluding carotid disease. Hypertension was defined as blood pressure $>140 / 90 \mathrm{~mm} \mathrm{Hg}$ or the use of antihypertensive medication. Severe pulmonary hypertension was defined as mean invasive pulmonary artery pressure $>40 \mathrm{~mm} \mathrm{Hg}$. Chronic lung disease was defined as chronic obstructive pulmonary disease, asthma, or pulmonary fibrosis. Normal, moderate, or poor left ventricular function was defined as left ventricular ejection fraction $\geq 50, \geq 30<50 \%$, or $<30 \%$, respectively (on echocardiography). No, mild/moderate, or severe left ventricular hypertrophy was defined as interventricular septal thickness of $<11 \mathrm{~mm}, 11$ to $15 \mathrm{~mm}$, or $>15 \mathrm{~mm}$, respectively (on echocardiography).

\section{Definitions of Adverse Events}

Adverse events were defined as follows. Transient ischemic attack was defined as focal neurologic deficit of sudden onset as diagnosed by a neurologist, lasting $<24$ hours with fully reversible symptoms. Ischemic stroke was defined as focal neurologic deficit of sudden onset as diagnosed by a neurologist, lasting $>24$ hours and caused by cerebral ischemia. Hemorrhagic stroke was defined as focal neurologic deficit of sudden onset as diagnosed by a neurologist, lasting $>24$ hours and caused by cerebral bleeding. Peripheral thromboembolism was defined as arterial thromboembolism to the viscera or extremities, excluding septic embolism. Minor bleeding was defined as bleeding not requiring admission or blood transfusion. Major bleeding was defined as fatal or nonfatal bleeding requiring admission or blood transfusion, excluding hemorrhagic stroke.

\section{Statistics}

Calculation of long-term survival was performed by Kaplan-Meier analysis. Identification of independent risk factors for decreased long-term survival was performed by Cox multiple regression analysis (forward stepwise technique). Death was not formally considered a competing risk but was treated as end of follow-up (ie, censor). Binary variables were labeled as yes versus no or missing. Missing data on categorical variables were categorized automatically into the lowest risk category. Continuous and dichotomous variables were analyzed with the Student $t$ or Mann-Whitney $U$ tests and $\chi^{2}$ tests, respectively. Two-sided tests of significance are reported, and $P$ values $<.05$ were considered statistically significant. Data were analyzed by SPSS version 20 for Windows (IBM Corp, Armonk, NY). 


\section{Variables Considered in Multivariable Analysis}

Variables considered in multivariable analysis for decreased long-term survival were a priori based on previous research and included age (continuous variable), sex, previous CABG, hypertension, moderate or severe left ventricular hypertrophy, chronic lung disease, previous ischemic stroke, peripheral arterial disease, insulin- or noninsulin-dependent diabetes, body mass index $<20$ or $\geq 30$, predominant aortic stenosis or regurgitation, biologic or mechanical AVR, moderate or poor left ventricular function, concomitant $\mathrm{CABG}$, recent or old myocardial infarction, serum creatinine (continuous variable), severe pulmonary hypertension, and new-onset POAF. ${ }^{16-18}$

\section{RESULTS}

\section{Baseline Characteristics}

Table 1 shows baseline characteristics of the patients with new-onset POAF versus those without. There were no significant differences between the 2subgroups, except the incidence of severe left ventricular hypertrophy, which was lower in the patients with new-onset POAF versus those without $(23.7 \%$ vs $32.0 \%, P=.031)$.

\section{Operative Characteristics, Postoperative In-Hospital Adverse Events, and Postoperative Hospital Lengths of Stay}

Table 2 shows operative characteristics, postoperative in-hospital adverse events, and postoperative hospital lengths of stay until discharge home in the patients with new-onset POAF versus those without. There were no significant differences between the 2 subgroups, except mechanical ventilation time, which was longer in the patients with new-onset POAF.

\section{Incidence of New-Onset POAF}

Incidence rates of new-onset POAF after isolated AVR and after AVR with concomitant CABG were $40.6 \%$ (165 of 406 patients) and $46.6 \%$ (76 of 163 patients), respectively. The incidence of new-onset POAF in the total study population was $42.4 \%$ ( 241 of 569 patients).

\section{Follow-up}

Mean follow-up was $17.8 \pm 1.9$ years. Follow-up was complete in all patients, except in one patient, who was lost to follow-up 18 months after AVR because of emigration. All other patients, including the 7 patients $(2.9 \%)$ with new-onset POAF who were still in AF at discharge, were followed for at least 15 years after AVR or until death.

\section{Thirty-Day Survival}

Thirty-day mortality in the patients with new-onset POAF was $1.2 \%$ ( 3 of 241 patients), versus $2.7 \%$ (9 of 328 patients $)$ in those without $(P=.25)$.

\section{Long-Term Survival}

During a mean follow-up of $17.8 \pm 1.9$ years, a total of 169 of 241 patients $(70.1 \%)$ with new-onset POAF and 231 of 328 patients $(70.4 \%)$ without new-onset POAF died. Causes of death were cardiac related in $37.3 \%$ of patients with new-onset POAF versus $32.5 \%$ in those without $(P=.339)$. Kaplan-Meier overall cumulative survival curves of the patients with new-onset POAF versus those without are shown in Figure 1. There was no statistically significant difference between the 2 survival curves (logrank: $P=.6$ ). Kaplan-Meier overall cumulative survival rates at 15 years of follow-up in the patients with newonset POAF versus those without were similar: $41.5 \%$ (95\% CI, 35.2-47.7) versus $41.3 \%$ (95\% CI, 36.0-46.7), respectively.

Because the Kaplan-Meier survival graph indicated an early high hazard phase merging into a phase of lower risk, we segmented the follow-up time for each patient in slices of 1 year and did a Cox proportional hazards analysis with new-onset POAF as risk factor together with the interaction term "new-onset POAF" and start time of the interval (relative to the day of surgery). The $P$ value for the interaction term was .19, indicating that the effect of newonset POAF on long-term survival was not statistically significant and remained stable over time.

Independent risk factors for decreased long-term survival are depicted in Table 3. These were, in order of decreasing significance: previous $\mathrm{CABG}$, poor or moderate left ventricular function, peripheral arterial disease, insulin- or noninsulin-dependent diabetes, greater age, and a greater serum creatinine. New-onset POAF was not an independent risk factor for decreased long-term survival (hazard ratio $0.815 ; 95 \%$ CI, 0.663-1.001; $P=.052$ ).

In the subgroups of male versus female patients, patients older than versus younger than 65 years of age, and patients with isolated AVR versus AVR with concomitant CABG, new-onset POAF was not an independent risk factor for decreased long-term survival because the $P$ values for effect modification of new-onset POAF and these variables were $.73, .78$, and .09 , respectively.

\section{Long-Term First Adverse Events}

Table 4 shows cumulative 18-year probability figures of long-term first adverse events in the patients with newonset POAF versus those without. Cumulative probability of a first event of (recurrent) AF, transient ischemic attack, ischemic or hemorrhagic stroke, peripheral thromboembolism, or minor or major bleeding at 18 years of follow-up was not significantly different between the 2 subgroups.

\section{DISCUSSION}

This study demonstrated that new-onset POAF after AVR did not affect long-term survival when treatment was aimed to restore sinus rhythm within 24 to 48 hours from onset by medication and when medication failed by direct-current cardioversion before discharge home (Figure 2). The mean follow-up of $17.8 \pm 1.9$ years is, as far as we know, the longest follow-up of new-onset POAF after cardiac 
TABLE 1. Baseline characteristics

\begin{tabular}{|c|c|c|c|}
\hline & $\begin{array}{c}\text { New-onset postoperative } \\
\text { atrial fibrillation }(n=241)\end{array}$ & $\begin{array}{l}\text { No new-onset postoperative } \\
\text { atrial fibrillation }(n=328)\end{array}$ & $P$ value \\
\hline Age, y & $65.4 \pm 10.7$ & $64.1 \pm 10.9$ & .158 \\
\hline Male & $134(55.6)$ & $185(56.4)$ & .865 \\
\hline Logistic EuroSCORE & $4.7 \pm 3.8$ & $4.9 \pm 5.9$ & .747 \\
\hline EuroSCORE II & $2.2 \pm 2.1$ & $2.2 \pm 3.0$ & .995 \\
\hline Society of Thoracic Surgeons Score & $1.8 \pm 1.3$ & $1.7 \pm 1.6$ & .635 \\
\hline \multicolumn{4}{|l|}{ New York Heart Association Class } \\
\hline I & $28(11.6)$ & $36(11.0)$ & .893 \\
\hline II & $95(39.4)$ & $129(39.3)$ & 1.000 \\
\hline III & $96(39.8)$ & $138(42.1)$ & .606 \\
\hline IV & $22(9.1)$ & $25(7.6)$ & .540 \\
\hline Concomitant CABG & $76(31.5)$ & $87(26.5)$ & .222 \\
\hline Mechanical AVR & $149(61.8)$ & $226(68.9)$ & .089 \\
\hline Previous CABG & $11(4.6)$ & $11(3.4)$ & .513 \\
\hline Recent myocardial infarction* & $5(2.1)$ & $5(1.5)$ & .750 \\
\hline Old myocardial infarction* & $28(11.6)$ & 39 (11.9) & 1.000 \\
\hline Previous ischemic stroke & $9(3.7)$ & $11(3.4)$ & .821 \\
\hline Peripheral arterial disease* & $15(6.2)$ & $25(7.6)$ & .619 \\
\hline Serum creatinine, $\mu \mathrm{mol} / \mathrm{L} / \mathrm{mg} / \mathrm{dL}$ & $98.2 \pm 59.3 / 1.1 \pm 0.7$ & $94.7 \pm 22.9 / 1.1 \pm 0.3$ & .328 \\
\hline Dialysis & $2(0.8)$ & 0 & .179 \\
\hline Hypertension* & $126(52.3)$ & $159(48.5)$ & .397 \\
\hline Severe pulmonary hypertension* & $9(3.7)$ & $12(3.7)$ & 1.000 \\
\hline Unknown & $47(19.5)$ & $87(26.5)$ & \\
\hline Insulin-dependent diabetes & $6(2.5)$ & $10(3.0)$ & .801 \\
\hline Noninsulin-dependent diabetes & $17(7.1)$ & $29(8.8)$ & .534 \\
\hline Chronic lung disease* & $31(12.9)$ & $35(10.7)$ & .430 \\
\hline Predominant aortic stenosis & $204(84.6)$ & $276(84.1)$ & .907 \\
\hline \multicolumn{4}{|l|}{ Aortic insufficiency $\dagger$} \\
\hline No & $59(24.5)$ & $92(28.0)$ & .379 \\
\hline Mild & $53(22.0)$ & $84(26.5)$ & .231 \\
\hline Moderate & $55(22.8)$ & $63(19.2)$ & .291 \\
\hline Severe & $53(22.0)$ & $58(17.7)$ & .196 \\
\hline Unknown & $21(8.7)$ & $28(8.5)$ & \\
\hline Peak gradient, mm $\mathrm{Hg} \dagger$ & $80 \pm 31$ & $81 \pm 29$ & .634 \\
\hline Unknown & $30(12.4)$ & $50(15.2)$ & \\
\hline Aortic valve area, $\mathrm{cm}^{2} \dagger$ & $0.76 \pm 0.30$ & $0.79 \pm 0.64$ & .637 \\
\hline Unknown & $129(53.5)$ & $169(51.5)$ & \\
\hline \multicolumn{4}{|l|}{ Left ventricular function* } \\
\hline Normal & $209(86.7)$ & 277 (84.5) & .473 \\
\hline Moderate & $22(9.1)$ & $36(11.0)$ & .488 \\
\hline Poor & $10(4.1)$ & $15(4.6)$ & .840 \\
\hline \multicolumn{4}{|l|}{ Left ventricular hypertrophy* } \\
\hline No & $104(43.2)$ & $129(39.3)$ & .389 \\
\hline Mild/moderate & $80(33.2)$ & $94(28.7)$ & .269 \\
\hline Severe & $57(23.7)$ & $105(32.0)$ & .031 \\
\hline Body mass index, $\mathrm{kg} / \mathrm{m}^{2}$ & $25.7 \pm 3.1$ & $25.6 \pm 3.4$ & .579 \\
\hline$<20$ & $2(0.8)$ & $3(0.9)$ & 1.000 \\
\hline$\geq 20<30$ & $211(87.6)$ & $290(88.4)$ & .794 \\
\hline$\geq 30$ & $28(11.6)$ & $35(10.7)$ & .787 \\
\hline
\end{tabular}

Values are presented as mean \pm standard deviation or $\mathrm{n}(\%)$. EuroSCORE, European System for Cardiac Operative Risk Evaluation; CABG, coronary artery bypass grafting; $A V R$, aortic valve replacement. *See text for definition. $\dagger$ On echocardiography.

surgery ever, almost twice as long as in the literature. In the present study, new-onset POAF after AVR was not associated with decreased 30-day survival.
Known risk factors for the occurrence of POAF after cardiac surgery include older age, hypertension, a history of AF, congestive heart failure, significant left ventricular 
TABLE 2. Operative characteristics, postoperative in-hospital adverse events, and postoperative hospital lengths of stay

\begin{tabular}{|c|c|c|c|}
\hline & $\begin{array}{c}\text { New-onset postoperative atrial } \\
\text { fibrillation }(n=241)\end{array}$ & $\begin{array}{l}\text { No new-onset postoperative } \\
\text { atrial fibrillation }(n=328)\end{array}$ & $P$ value \\
\hline \multicolumn{4}{|l|}{ Operative characteristics } \\
\hline Aortic crossclamp time, min, mean $\pm \mathrm{SD}$ & $74.7 \pm 27.3$ & $74.1 \pm 28.4$ & .810 \\
\hline Cardiopulmonary bypass time, min, mean \pm SD & $109.6 \pm 61.9$ & $107.3 \pm 52.3$ & .633 \\
\hline Mechanical ventilation time, $\mathrm{h}$, median (IQR)* & $18(13,22)$ & $16(11,20)$ & .011 \\
\hline \multicolumn{4}{|l|}{ Postoperative in-hospital adverse events $\dagger$} \\
\hline Inotropic therapy & $16(6.6)$ & $20(6.1)$ & .862 \\
\hline Mediastinitis & $2(0.8)$ & 0 & .179 \\
\hline Cardiac tamponade & $16(6.6)$ & $17(5.2)$ & .473 \\
\hline Myocardial infarction & 0 & $1(0.3)$ & 1.000 \\
\hline Permanent pacemaker implantation & $8(3.3)$ & $4(1.2)$ & .137 \\
\hline Transient ischemic attack & $2(0.8)$ & $1(0.3)$ & .577 \\
\hline Ischemic stroke & $4(1.7)$ & $4(1.2)$ & .727 \\
\hline Hemorrhagic stroke & 0 & 0 & \\
\hline Major bleeding & $2(0.8)$ & $3(0.9)$ & 1.000 \\
\hline $\begin{array}{l}\text { Postoperative hospital length of stay until discharge } \\
\text { home, d, median (IQR)* } \neq\end{array}$ & $12(12,17)$ & $13(12,18)$ & .210 \\
\hline Range & $8-91$ & $8-96$ & \\
\hline
\end{tabular}

$S D$, Standard deviation; $I Q R$, interquartile range. *Mann-Whitney $U$ test. †Values are presented as $n(\%)$. $\ddagger$ Including stay in referring hospital or rehabilitation center, when necessary.

hypertrophy, and possibly prolonged aortic crossclamp and mechanical ventilation times. ${ }^{19-23}$ In the present study, these risk factors were not more prevalent in the patients with new-onset POAF versus those without, except mechanical ventilation times, which were longer in the patients with new-onset POAF. The reason for this discrepancy with the literature is possibly the homogeneous group of study patients regarding cardiac history (no history of AF) and kind of cardiac surgery (all AVR, mostly without

\section{Survival}

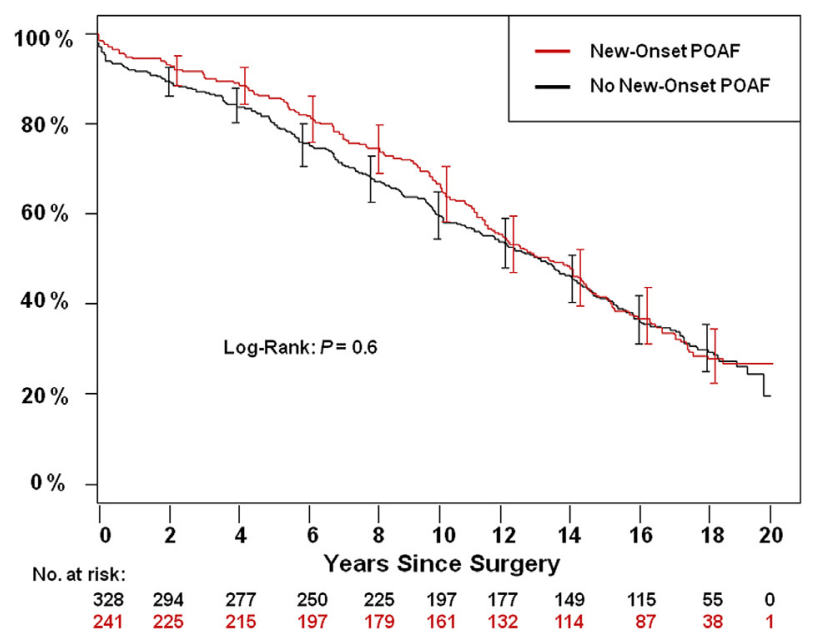

FIGURE 1. Kaplan-Meier overall cumulative survival curves of the patients with new-onset POAF after aortic valve replacement ( red line) versus those without (black line), with a mean follow-up of $17.8 \pm 1.9$ years. $P O A F$, Postoperative atrial fibrillation. concomitant $\mathrm{CABG}$ ). This finding is in contrast to patients with POAF in the literature, who were mostly patients with or without a history of AF and who mostly underwent CABG, with or without concomitant valve surgery. Possibly, new-onset POAF is in part related to the thoracotomy or cardiopulmonary bypass procedures, because catheter-based AVR recently was associated with a lower incidence of new-onset POAF. ${ }^{24}$

Based on the similar first adverse event rates in the present study of (recurrent) AF, transient ischemic attack, ischemic or hemorrhagic stroke, peripheral thromboembolism, and minor or major bleeding during long-term

TABLE 3. Independent risk factors for decreased long-term survival

\begin{tabular}{|c|c|c|c|}
\hline Risk factor & $\begin{array}{c}\text { Hazard } \\
\text { ratio }\end{array}$ & $\begin{array}{c}95 \% \text { Confidence } \\
\text { interval }\end{array}$ & $P$ value \\
\hline Previous CABG & 2.680 & $1.692-4.244$ & $<.001$ \\
\hline Left ventricular function* & & & $.001 \dagger$ \\
\hline Poor & 1.702 & $1.053-2.750$ & .030 \\
\hline Moderate & 1.651 & $1.202-2.268$ & .002 \\
\hline Normal & 1.000 & Reference & Reference \\
\hline Peripheral arterial disease & 1.572 & $1.108-2.230$ & .013 \\
\hline Diabetes & & & $.014 \dagger$ \\
\hline Insulin dependent & 1.689 & $0.984-2.899$ & .057 \\
\hline Noninsulin dependent & 1.484 & $1.050-2.097$ & .025 \\
\hline No diabetes & 1.000 & Reference & Reference \\
\hline Age & $1.077 \ddagger$ & $1.063-1.091$ & $<.001$ \\
\hline Serum creatinine & $1.003 \S$ & $1.001-1.004$ & .002 \\
\hline
\end{tabular}


TABLE 4. Cumulative probability of long-term first adverse events at 18 years of follow-up

\begin{tabular}{|c|c|c|c|}
\hline $\begin{array}{c}\text { Cumulative probability of long-term first adverse } \\
\text { event at } 18 \text { y of follow-up }(\%, 95 \% \text { confidence } \\
\text { interval) }\end{array}$ & $\begin{array}{c}\text { New-onset postoperative } \\
\text { atrial fibrillation }(n=241)\end{array}$ & $\begin{array}{l}\text { No new-onset postoperative } \\
\text { atrial fibrillation }(n=328)\end{array}$ & $P$ value \\
\hline (Recurrent) atrial fibrillation & $36.7(27.4-44.9)$ & $35.9(28.0-43.0)$ & 1.000 \\
\hline Transient ischemic attack & $17.8(10.0-25.0)$ & $15.3(8.7-21.3)$ & .843 \\
\hline Ischemic stroke & $13.8(7.9-19.4)$ & $14.7(8.6-20.4)$ & .945 \\
\hline Hemorrhagic stroke & $10.2(4.9-15.2)$ & $10.9(6.3-15.2)$ & .713 \\
\hline Peripheral thromboembolism & $0.0(0.0-0.0)$ & $1.2(0.0-2.5)$ & .311 \\
\hline Minor bleeding & $49.2(39.0-57.7)$ & $48.2(39.7-55.5)$ & .994 \\
\hline Major bleeding & $39.6(29.8-48.0)$ & $39.3(30.8-46.7)$ & .795 \\
\hline
\end{tabular}

follow-up in the patients with new-onset POAF versus those without, combined with our finding that new-onset POAF did not affect long-term survival, we think that new-onset POAF after AVR can be considered to be a temporary disorder without adverse consequences on the long term. However, this does not imply that new-onset POAF after AVR can be left untreated, because the findings of the present study are based on patients treated with the aim to restore sinus rhythm within 24 to 48 hours from onset by medication and when medication failed by direct-current cardioversion before discharge home. This policy also conforms to the current 2014 American Association for Thoracic Surgery and 2014 American College of Cardiology/American Heart Association/Heart Rhythm Society guidelines on new-onset POAF. ${ }^{25,26}$ Striving for sinus rhythm as soon as possible when new-onset POAF occurs also is supported by a recent study that demonstrated that in a porcine model the left atrium underwent significant structural remodeling and decreased contractility after 6 weeks of AF. ${ }^{27}$

\section{Limitations}

A limitation of the present study is that we, because of its retrospective design, did not study patients with different treatment strategies on new-onset POAF. Therefore, we

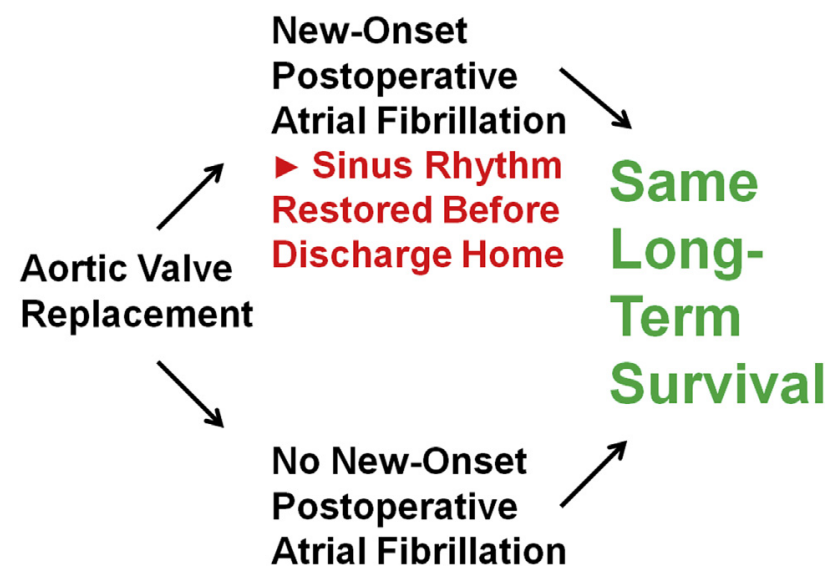

FIGURE 2. New-onset postoperative atrial fibrillation does not affect long-term survival. do not know whether the findings of the present study would still be valid in the event that new-onset POAF was treated in another way than in the present study. Another limitation is that we studied the effect of new-onset POAF only in patients undergoing AVR with or without concomitant $\mathrm{CABG}$, not in patients undergoing isolated $\mathrm{CABG}$ or valve surgery other than AVR. A third limitation is the restricted inclusion period (because of limited financing) of 1990 to 1994 . However, although more contemporary data would have been very useful to confirm the conclusions of the present study, the restricted inclusion period may have made the study population more homogeneous regarding surgical techniques than it would have been with inclusion right up to date. Also, because of the restricted inclusion period, all study patients were followed for at least 15 years after AVR.

\section{CONCLUSIONS}

New-onset POAF after AVR does not affect long-term survival when treatment is aimed to restore sinus rhythm before the patient is discharged home. Future studies with a prospective randomized design should be done to confirm this finding in patients undergoing different kinds of cardiac surgery.

\section{Conflict of Interest Statement}

Authors have nothing to disclose with regard to commercial support.

The authors thank Edgar J. Daeter, MD, Department of Cardiothoracic Surgery, St Antonius Hospital, Nieuwegein, The Netherlands, for producing the video of an AVR procedure, which is available on the Web site of the Journal of Thoracic and Cardiovascular Surgery. The authors also thank Yvonne van Hees, MSc, for her efforts in developing the databases and entering data. Furthermore, we are grateful to Diane Vermeulen, MD, MSc, for her efforts in entering data, and to Geert J. M. G. van der Heijden, $\mathrm{PhD}, \mathrm{MS}$, and Henry A. van Swieten, $\mathrm{MD}, \mathrm{PhD}$, for their efforts in developing the databases.

\section{References}

1. Ommen SR, Odell JA, Stanton MS. Atrial arrhythmias after cardiothoracic surgery. N Engl J Med. 1997;336:1429-34. 
2. Maisel WH, Rawn JD, Stevenson WG. Atrial fibrillation after cardiac surgery Ann Intern Med. 2001;135:1061-73.

3. Pires LA, Wagshal AB, Lancey R, Huang SK. Arrhythmias and conduction disturbances after coronary artery bypass graft surgery: epidemiology, management, and prognosis. Am Heart J. 1995;129:799-808.

4. Melby SJ, George JF, Picone DJ, Wallace JP, Davies JE, George DJ, et al. A timerelated parametric risk factor analysis for postoperative atrial fibrillation after heart surgery. J Thorac Cardiovasc Surg. 2015;149:886-92.

5. Bramer S, ter Woorst J, van Geldorp MW, van den Broek KC, Maessen JG, Berreklouw E, et al. Does new-onset postoperative atrial fibrillation after coronary artery bypass grafting affect postoperative quality of life? J Thorac Cardiovasc Surg. 2013;146:114-8.

6. Villareal RP, Hariharan R, Liu BC, Kar B, Lee VV, Elayda M, et al. Postoperative atrial fibrillation and mortality after coronary artery bypass surgery. J Am Coll Cardiol. 2004;43:742-8.

7. Almassi GH, Schowalter T, Nicolosi AC, Aggarwal A, Moritz TE, Henderson WG, et al. Atrial fibrillation after cardiac surgery: a major morbid event? Ann Surg. 1997;226:501-11.

8. Bramer S, van Straten AH, Soliman Hamad MA, Berreklouw E, Martens EJ, Maessen JG. The impact of new-onset postoperative atrial fibrillation on mortality after coronary artery bypass grafting. Ann Thorac Surg. 2010;90:443-50.

9. Kalavrouziotis D, Buth KJ, Ali IS. The impact of new-onset atrial fibrillation on in-hospital mortality following cardiac surgery. Chest. 2007;131:833-9.

10. Ahlsson A, Bodin L, Fengsrud E, Englund A. Patients with postoperative atrial fibrillation have a doubled cardiovascular mortality. Scand Cardiovasc J. 2009; 43:330-6.

11. Ahlsson A, Fengsrud E, Bodin L, Englund A. Postoperative atrial fibrillation in patients undergoing aortocoronary bypass surgery carries an eightfold risk of future atrial fibrillation and a doubled cardiovascular mortality. Eur J Cardiothorac Surg. 2010;37:1353-9.

12. Mariscalco G, Klersy C, Zanobini M, Banach M, Ferrarese S, Borsani P, et al Atrial fibrillation after isolated coronary surgery affects late survival. Circulation. 2008;118:1612-8.

13. Saxena A, Dinh DT, Smith JA, Shardey GC, Reid CM, Newcomb AE. Usefulness of postoperative atrial fibrillation as an independent predictor for worse early and late outcomes after isolated coronary artery bypass grafting (multicenter Australian study of 19,497 patients). Am J Cardiol. 2012;109:219-25.

14. Mariscalco G, Engström KG. Postoperative atrial fibrillation is associated with late mortality after coronary surgery, but not after valvular surgery. Ann Thorac Surg. 2009;88:1871-6.

15. Melduni RM, Schaff HV, Bailey KR, Cha SS, Ammash NM, Seward JB, et al Implications of new-onset atrial fibrillation after cardiac surgery on long-term prognosis: a community-based study. Am Heart J. 2015;170:659-68.

16. de Waard GA, Jansen EK, de Mulder M, Vonk AB, Umans VA. Long-term outcomes of isolated aortic valve replacement and concomitant AVR and coronary artery bypass grafting. Neth Heart J. 2012;20:110-7.
17. Tjang YS, van Hees Y, Körfer R, Grobbee DE, van der Heijden GJ. Predictors of mortality after aortic valve replacement. Eur J Cardiothorac Surg. 2007;32: 469-74

18. Verheul HA, van den Brink RB, Bouma BJ, Hoedemaker G, Moulijn AC, Dekker E, et al. Analysis of risk factors for excess mortality after aortic valve replacement. J Am Coll Cardiol. 1995;26:1280-6.

19. Aranki SF, Shaw DP, Adams DH, Rizzo RJ, Couper GS, VanderVliet M, et al. Predictors of atrial fibrillation after coronary artery surgery. Current trends and impact on hospital resources. Circulation. 1996;94:390-7.

20. Zaman AG, Archbold A, Helft G, Paul EA, Curzen NP, Mills PG. Atrial fibrillation after coronary artery bypass surgery: a model for preoperative risk stratification. Circulation. 2000;101:1403-8.

21. Frost L, Mølgaard H, Christiansen EH, Hjortholm K, Paulsen PK, Thomsen PE. Atrial fibrillation and flutter after coronary artery bypass surgery: epidemiology, risk factors and preventive trials. Int J Cardiol. 1992;36: 253-61

22. Mathew JP, Fontes ML, Tudor IC, Ramsay J, Duke P, Mazer CD, et al Investigators of the Ischemia Research and Education Foundation; Multi center Study of Perioperative Ischemia Research Group. A multicenter risk index for atrial fibrillation after cardiac surgery. JAMA. 2004;291: 1720-9.

23. Vaziri SM, Larson MG, Benjamin EJ, Levy D. Echocardiographic predictors of nonrheumatic atrial fibrillation. The Framingham Heart Study. Circulation. 1994:89:724-30.

24. Tanawuttiwat T, O'Neill BP, Cohen MG, Chinthakanan O, Heldman AW, Martinez CA, et al. New-onset atrial fibrillation after aortic valve replacement: comparison of transfemoral, transapical, transaortic, and surgical approaches. $J$ Am Coll Cardiol. 2014:63:1510-9.

25. Frendl G, Sodickson AC, Chung MK, Waldo AL, Gersh BJ, Tisdale JE, et al 2014 AATS guidelines for the prevention and management of perioperative atria fibrillation and flutter for thoracic surgical procedures. J Thorac Cardiovasc Surg. 2014;148:772-91.

26. January CT, Wann LS, Alpert JS, Calkins H, Cigarroa JE, Cleveland JC, et al 2014 AHA/ACC/HRS guideline for the management of patients with atrial fibrillation: a report of the American College of Cardiology/American Heart Association Task Force on Practice Guidelines and the Heart Rhythm Society. J Am Coll Cardiol. 2014;64:e1-76.

27. Kazui T, Henn MC, Watanabe Y, Kovacs SJ, Lawrance CP, Greenberg JW, et al The impact of 6 weeks of atrial fibrillation on left atrial and ventricular structure and function. J Thorac Cardiovasc Surg. 2015;150:1602-8.

Key Words: aortic valve replacement, coronary artery bypass surgery, survival, atrial fibrillation, perioperative management, direct-current cardioversion 